This item was submitted to Loughborough's Research Repository by the author.

Items in Figshare are protected by copyright, with all rights reserved, unless otherwise indicated.

\title{
Predicting in situ heat pump performance: an investigation into a single ground-source heat pump system in the context of 10 similar systems
}

PLEASE CITE THE PUBLISHED VERSION

http://dx.doi.org/10.1016/j.enbuild.2012.03.001

PUBLISHER

(C) Elsevier

VERSION

AM (Accepted Manuscript)

LICENCE

CC BY-NC-ND 4.0

\section{REPOSITORY RECORD}

Stafford, A., and Debra Lilley. 2019. "Predicting in Situ Heat Pump Performance: An Investigation into a Single Ground-source Heat Pump System in the Context of 10 Similar Systems". figshare.

https://hdl.handle.net/2134/11816. 
This item was submitted to Loughborough's Institutional Repository (https://dspace.lboro.ac.uk/) by the author and is made available under the following Creative Commons Licence conditions.

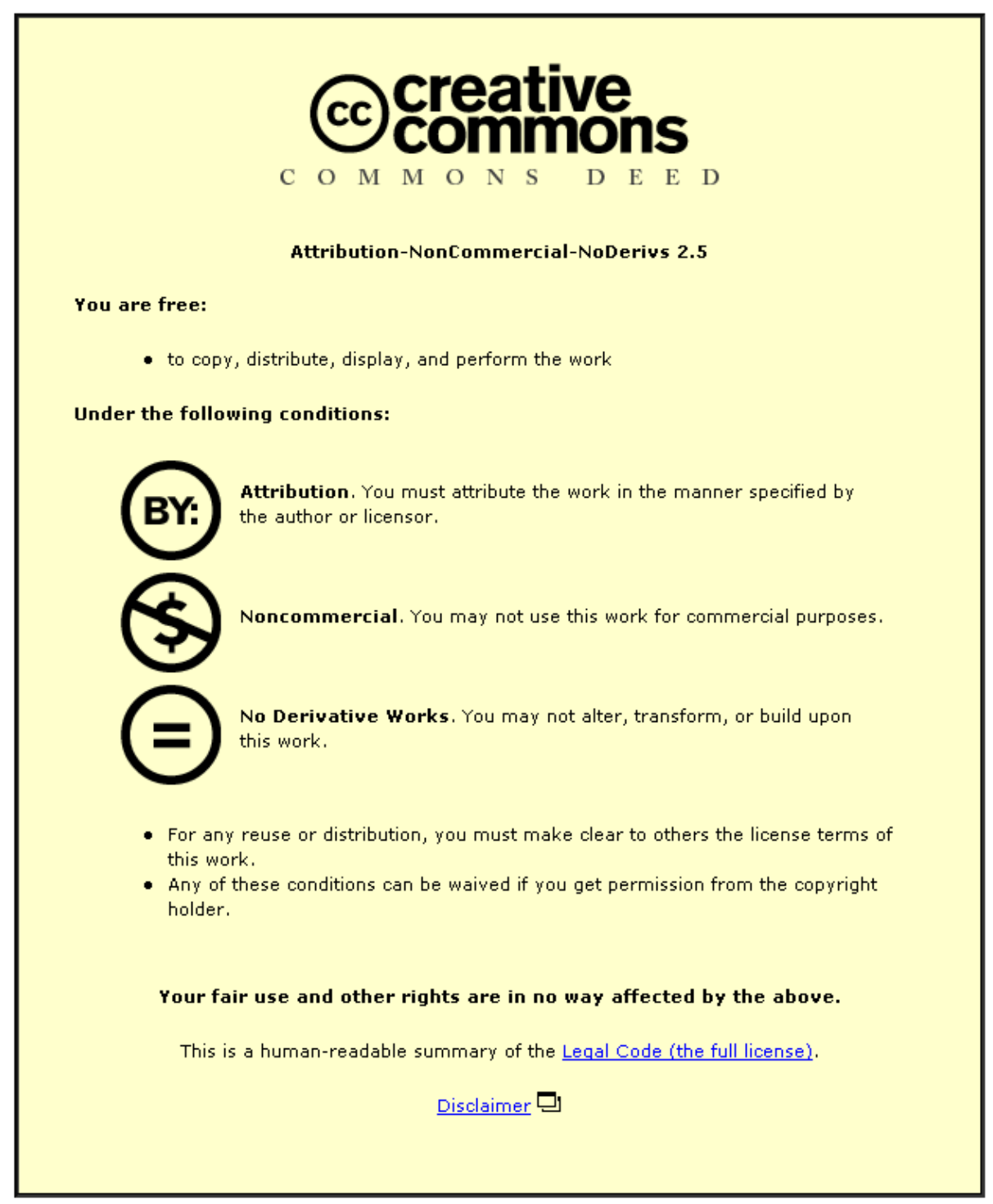

For the full text of this licence, please go to: http://creativecommons.org/licenses/by-nc-nd/2.5/ 


\title{
Predicting In-situ Heat Pump Performance: An Investigation into a Single Ground-Source Heat Pump system in the context of 10 similar systems.
}

\author{
A. Stafford ${ }^{a^{*}}$ and D. Lilley \\ ${ }^{a}$ Centre for the Built Environment, Leeds Metropolitan University, Northern Terrace, \\ Queen Square Court, Leeds LS2 8AG \\ boughborough Design School, Loughborough University, LE11 3TU \\ *Corresponding author: Tel: +44-113-812-7623, Fax: +44-113-812-1958 Email: \\ a.stafford@leedsmet.ac.uk
}

\begin{abstract}
Ten similar ground-source heat pump systems installed in small rural social housing bungalows in the UK have been monitored in detail over a period of more than one year. The purpose of the present work was to take one system at random, and study its performance characteristics in the context of the group, in order to explore the potential for predicting performance from a few readily obtainable parameters. The chosen system performed relatively well in summer and relatively poorly in winter (despite an average temperature lift for space-heating). This was found to be readily explicable in terms of domestic hot water set-point temperature, and compressor cycling behaviour. The latter may be affected by building fabric issues, or by user behaviour (e.g. windowopening). The study suggests that where sizeable groups of similar systems are installed in similar buildings (e.g. by social housing providers), an appropriate monitoring strategy may be to monitor a sample of installations in detail, and to predict the performance of the remainder based on limited but more easily obtained data. However, the limited dataset may need to include internal and ground-loop fluid temperatures, heat pump electricity consumption, and some detailed knowledge of building fabric and occupier practices.
\end{abstract}

Keywords: Ground-source Heat Pumps; Building Fabric Performance; Seasonal Performance Factor; Energy Monitoring. 


\section{Introduction}

Heat Pump systems are expected to form a rapidly-growing element of domestic spaceheating and hot water production in the UK, especially for off gas-grid properties, due at least in part to the proposed introduction of the Renewable Heat Incentive (RHI) payments in 2012 [1]. Under this scheme, owners of eligible technologies will receive a guaranteed payment over a period of time depending on the set rate at the time of installation, and the amount of heat generated. There is also provision for an interim scheme providing one-off payments to support new installations in eligible dwellings (i.e. off gas-grid). These so-called premium payments will be available between $1^{\text {st }}$ August 2011 and 31 ${ }^{\text {st }}$ March 2012.

However, evidence is emerging that heat pumps may be underperforming in the UK compared with other European countries [2]. If this is the case, it may result in RHI payments being made in respect of technologies which are not, or are only marginally, carbon-saving. Furthermore, in the case of Registered Social Landlords (RSLs), for example, the owners of the technology who will receive the benefits of RHI support are not the users, who may be vulnerable groups, and may be subject to higher fuel costs than would be the case if the systems were performing as expected. This could lead to an anomalous situation where the interests of the two groups did not in fact coincide. It is therefore very important to fully understand the factors affecting performance of ground-source heat pumps in the UK, with a view to improving performance at the installed system level.

In this study a group of ten similar systems installed in small social-housing dwellings were studied in depth for a period of over one year. The present paper focuses on a detailed case study of one of these systems (chosen at random) in the context of the group. The aim is to identify as far as possible the main factors affecting relative performance, in order to assess the possibility of predicting relative performance from a knowledge of a limited set of easily 
measured parameters, and also to cast light upon some of the issues which need to be considered particularly carefully by system designers, certificated installers, landlords, owner-adopters and other stakeholders.

The systems were studied using both technical energy-monitoring, and social/behavioural investigations, thus enabling insights into the effects of a range of factors. The authors believe that this combined socio-technical approach will be vital in gaining appropriate understanding of these complex issues.

The ten systems studied consisted of IVT Greenline C6 heat pumps, capable of delivering both space-heating (SH) and domestic hot water (DHW), and supplemented by an internal electric cassette, brought incrementally online (at $3 \mathrm{~kW}$ or $6 \mathrm{~kW}$ ) if and when necessary. In practice, this only occurred during the weekly pasteurisation cycle (when the hot water tank temperature is raised temporarily to $60^{\circ} \mathrm{C}$ in order to mitigate the risk from legionella bacteria). All the heat pumps had borehole collectors and were connected to conventional wet radiator heating systems, with replacement radiators which were oversized by about $30 \%$ as part of the heat pump installation procedure, in order to compensate for lower surface temperatures.

The dwellings were also similar, being small bungalows built between 1960 and 1987, and let by the local authority as social housing for the elderly. Prior to the installation of the heat pumps, the dwellings were upgraded to exceed Decent Homes standard [3], with improvements including double-glazing, increased loft insulation and cavity-wall insulation.

Details of the monitoring scheme and equipment have been published elsewhere [4].

The system which forms the main subject of this case study (designated system A) was chosen at random from the group of 10 . 


\section{Results and Discussion}

2.1 Performance of System A, relative to the other 9 systems

An annual Seasonal Performance Factor (SPF) was calculated for all 10 systems, by measuring the total annual electrical consumption (E) of the heat pump system (including back-up heater and both the ground-loop pump and the hot-side distribution pump), and the total heat output (Q) (to both space-heating and DHW), for the year $1^{\text {st }}$ March 2010 to $28^{\text {th }}$ February 2011.

\section{Annual SPF $=\mathrm{Q} / \mathrm{E}$}

This particular time period was chosen as the most appropriate full annual cycle which predated the initiation of any interventions designed to alter behaviour or control strategies within the group.

The SPF as calculated above is consistent with the definition of SPF4 described in the Technical Research Institute of Sweden report on SPF calculation methods [5], i.e. the system boundary includes the ground-loop pump, the electric cassette (back-up heater) and also the hot-side distribution pump. Although the use of this system boundary results in lower apparent system SPFs than would be the case for a system boundary which excluded the distribution pump, it has been chosen in the case of this particular discussion for two reasons. Firstly, for these systems the distribution pump is integral (contained within the physical heat pump enclosure), and secondly, the focus of interest is on the performance of whole systems in-situ.

Calculating the annual SPF as described above, results in a value of 2.22 for system A. The corresponding figures for the other systems range from 1.99 to 2.54 with an average of 2.20 
and a median between 2.09 and 2.16. Thus the performance factor of system $\mathrm{A}$ is around the average for the group, and would need to be improved by almost $15 \%$ in order to match that of the best performing system.

Fig 1 shows the performance factor of system A on a month by month basis, during this year. The spread of values from all 10 systems is also shown in the diagram.

Whilst system A is at no time the best or worst performing system in the group, Fig 1 shows that it is performing relatively well during the summer months, when many of the systems show a significant drop in performance (due to the output being dominated by DHW production). Similarly, the performance in the winter months is relatively poor compared with the other nine systems. In itself this might suggest that this system is producing DHW relatively efficiently, and space heating relatively inefficiently compared with the remainder of the group.

Fig 2 shows a similar plot for the total electrical consumption of the heat pumps on a month by month basis.

Again, system A is at no time the maximum or minimum consumer of electricity within the group of 10 systems, but this time it is clear that during the colder months the consumption tends to be somewhat higher than average. Conversely during the summer months consumption is somewhat below average.

Thus both Fig 1 and Fig 2 suggest that the heat pump system A is performing relatively well with respect to DHW production.

(Note that 4 days of consumption data for system A during October is missing due to a faulty transmitter, so this data point represents a slight underestimate of actual consumption). 


\subsection{Factors Affecting Performance}

Heat pump performance is driven to a large extent by the temperature lift, i.e. the temperature difference between input from the ground loop and output to space-heating or DHW. The latter is usually required to be provided at a higher temperature than the demand temperatures of the space-heating circuit, leading to generally lower efficiencies for heating DHW. However, space-heating demand temperatures are variable depending inversely upon the external temperature, according to a pre-set slope, in order to maintain a constant indoor environment. Furthermore, on the input side, the temperature of fluid from the ground loop will depend to some extent on time of year, as well as on borehole sizing, local geology and quality of thermal contact.

Other factors which may affect performance are compressor cycling, building fabric performance, and behavioural differences. In the following sections, these factors are considered for System A in context.

\subsection{Domestic Hot Water Temperature}

From Figs 1 and 2, we might expect that the set-point temperature for DHW in system A is set relatively low (leading to good efficiency and low electricity usage in the summer months). Fig 3 shows the daily average temperature as measured by surface probe at the top of the DHW tank for 9 of the 10 systems including System A. (The tenth system was excluded for reasons relating to system malfunctions). Clearly system A operates at a relatively low baseline DHW tank temperature as expected.

The regular peaks shown by the majority of systems represent weekly pasteurisation cycles where the tank temperature is raised briefly to $60^{\circ} \mathrm{C}$ to mitigate the risk of legionella growth. 
However, since these are daily average values (averaged from data sampled at 10 minute intervals), all temperatures shown on the plot are in fact less than $60^{\circ} \mathrm{C}$. There is a loss of pasteurisation cycle for one of the group from October onwards, but this is unrelated to the present discussion.

It should also be noted that in the case of system A, the heat pump (and hence the DHW tank) is located inside the thermal envelope of the dwelling. In some of the other dwellings they are located in unheated outhouse areas. Although the tanks are well-insulated, this combined with low DHW usage can result in significant tank losses [6].

\subsection{Space Heating}

Taking a simple view we might expect to see either fairly high internal dwelling temperatures, or low ground-loop temperatures, leading to relatively high electricity usage and lower efficiency during the heating season. Internal temperatures in the system A dwelling were measured in four locations (living room. bedroom, kitchen and bathroom) and found to be reasonably consistent and stable throughout the dwelling. Fig 4 shows living room and bedroom temperatures only for the sake of clarity, but kitchen and bathroom temperatures followed the living room temperature closely. The somewhat lower and less stable bedroom temperatures, during all of the year except for the coldest period in late November and December may be explained by the window-opening behaviour discussed in section 2.7.

Figs 5 and 6 track the living room temperatures and ground-loop fluid temperatures for all the systems. In the case of Fig 6 the plot is restricted to the months of November and December 2010. A full year plot would be misleading since during the warmer months, when the heat 
pump is operating intermittently, the temperature measured may represent only that of stagnant fluid in the pipework.

Figs 5 and 6 show that in the context of the other systems, system A is around average for both internal temperature and ground-loop fluid temperature. We might therefore expect to see average performance during the winter months, when the efficiency is dominated by space-heating, but in fact the performance tends to be below average. Factors which may cause this apparent anomaly are discussed in the following sections.

\subsection{Compressor Cycling}

In the small domestic heat pump systems studied, excessive on/off cycling is a factor which may significantly increase electricity consumption, due in part to the large start-up currents drawn by the compressor. However, cycling is also related to other issues such as building fabric performance or behavioural practices such as window opening which may lead to relatively rapid loss of heat from the building via increased ventilation losses. Alternatively it may be a result of the heat pump controls being set such that there is too narrow a temperature range between start-up and shut-off (hysteresis setting). The heat pumps are controlled by comparing return temperature from the radiator system with a target temperature calculated from external temperature and user-set requirements. The hysteresis is therefore the amount by which the return temperature is allowed to exceed or fall short of the target temperature before the compressor is automatically switched off or back on. In the following discussion we assume that the systems studied all retained the factory setting of $5^{\circ} \mathrm{C}$ for the hysteresis in the space heating controls (although there was some variation in the hysteresis and set-point temperatures for DHW). 
The compressor cycling behaviour in system A, together with the other 9 systems is illustrated by looking closely at a 2-day period $\left(1^{\mathrm{st}}-2^{\text {nd }}\right.$ October 2010). October was chosen as a period when space heating could be expected to occur, but on the other hand demand was not so constant as to blur the distinction between on and off periods. For each system, the total heat pump electricity consumption was plotted at 10 minute intervals, and the clear peaks simply counted. Fig 7 gives an example of the type of data obtained, showing the period 12 noon - 12 midnight on $1^{\text {st }}$ October for system A.

Whilst an element of human judgement exists in counting peaks in this way, it is nevertheless reasonably clear. Double peaks (i.e. where a shoulder exists on the main peak) are counted as one. It must be remembered however, that some of these peaks may be due to compressor start-up for the purpose of DHW production, and should therefore be discounted. It proved to be possible to separate the two by inspection using the data available in this study, since DHW tank temperature was monitored throughout, and so peaks coinciding with a rise in DHW temperature could be ascribed to DHW production. (DHW demand takes precedence over space-heating demand in these systems).

Table 1 shows the cycling behaviour of six of the ten systems (including system A), over the time period $1^{\text {st }}-2^{\text {nd }}$ October (48 hours). These six systems were all co-located on one street, and in dwellings of the same build type and age.

In fact, the table shows that during this two day period, System A underwent 52 spaceheating cycles; more than any of the other 5 systems except dwelling 6 which showed similar behaviour with 51 cycles. The remaining systems had numbers of space-heating cycles in the same period ranging from 19 to 39. Similar patterns could be observed for other time periods also, with system A (and dwelling 6) exhibiting relatively high cycling rates. This suggests 
that the dwelling which houses system A is losing heat relatively rapidly compared with most of the other dwellings.

\subsection{Building Fabric}

Since the dwelling was occupied throughout the monitoring period, it was not possible to measure the whole-house heat loss by means of a co-heating test [7]. However, a vacancy in one of the other dwellings (one of the group of ten, but not part of the sub-group of six), just prior to the period analysed, did allow such a test to take place. In the tested dwelling, the measured heat loss was reasonably close to that which would have been predicted for the dwelling from SAP (Standard Assessment Procedure) calculations, using appropriate Uvalues for the building age and type, and standard values for thermal bridging. It is not known however, to what extent the tested dwelling can be considered representative of the other dwellings in the group, despite the fact that all had been similarly upgraded.

It was, however, possible to perform pressurisation testing, using a standard fan and blower door [8], on the system A dwelling, the co-heating tested dwelling and dwelling 6 . The results in table 2 show that the air permeability is of the order of $6 \mathrm{~m}^{3} /\left(\mathrm{h} \cdot \mathrm{m}^{2}\right) @ 50 \mathrm{~Pa}$ for both the system A dwelling and the co-heating tested dwelling. This represents good performance for dwellings of this type and age, since it is well under the limit required by the 2006 Building Regulations (Part L) for new dwellings of $10 \mathrm{~m}^{3} /\left(\mathrm{h} . \mathrm{m}^{2}\right)$ @50Pa [9]. In contrast, the other dwelling tested (dwelling 6) showed much poorer performance in terms of air permeability, probably due to a number of poorly sealed service penetrations and other poorly sealed areas such as the outside roof/wall junction in the porch area. These potential problems were clearly apparent to a simple visual inspection. 
Unfortunately an energy performance certificate was not available for the system A dwelling. However two very similar nearby dwellings (not part of the heat pump study) were rated at 53 and 54 respectively (as compared with 55 for the co-heating tested dwelling). If we assume that the EPC rating for the system A dwelling would also be of this order, and assume further that the rating is a reasonable assessment of the thermal performance, then the presumption would be that we would not expect poorly performing building fabric to be a major influence on the relatively poor space-heating performance of the heat pump in the system A dwelling. However, simple factors such as badly-installed loft insulation can cause significant discrepancies between the theoretical rating and the real performance. The compressor cycling behaviour suggests relatively rapid heat loss, which could be due to fabric issues, or behavioural factors (such as window opening) or a combination of the two.

Fig 8 shows a plot of the cycling attributed to space-heating vs the estimated daily heat loss rate in $\mathrm{W} / \mathrm{K}$, (average of $1^{\text {st }}$ and $2^{\text {nd }}$ October). The latter was calculated from space-heating heat output and temperature difference as measured by internal and external temperature sensors. This method assumes that the heat production rate of the heat pump (for spaceheating) is equivalent to the heat loss rate from the building, which seems a reasonable assumption in view of the observed stability of internal temperatures. Of course it is understood that there will be other contributions to heat input to the building, such as metabolic and appliance gains, so the figures should not be taken as absolute values, but as indicative only.

Fig. 8 demonstrates that space-heating cycling rate can act as a good proxy for heat loss rate for these systems, under the conditions described. This is a potentially useful result since electricity consumption can be monitored more easily than heat output. 


\subsection{Behavioural Factors}

The user of system A did not adjust any of the default heat pump control settings which were put in place on commissioning of the system. However the occupant did habitually use window opening as a method of obtaining fresh air, despite reporting that the installers had advised keeping windows and doors closed when the heat pump was operating. Generally it was reported that a bedroom window was often open except in very cold weather. This is supported by the fact that bedroom temperatures are observably lower than other internal temperatures, except during the very cold period experienced in late November and December of 2010 when temperatures coincided much more closely (see Fig. 4) An open bedroom window may certainly be one source of increased heat loss, though it seems likely that in this case there may be additional fabric issues contributing also. Overall heat loss rates for the system A dwelling were similar to those for dwelling 6, which is known to have poorly performing fabric (see section 2.6), and it is known that the occupant of dwelling 6 refrains from opening windows during the heating season.

Radiators in all the properties were oversized by about 30\%, though one or two properties had requested an extra radiator in one location or another, thus increasing the emitter area further in these cases. No additional radiator was installed in the system A dwelling. The tenant reported no use of thermostatic radiator valves to adjust heating in specific rooms, and this was confirmed by observation during a visit. However, an oil-filled radiator in the hallway was used occasionally for the purpose of drying clothes. 


\section{Conclusions}

The relatively good DHW performance, (as evidenced by good performance factors during the summer months when there was little or no space heating required) could readily be explained by reference to the DHW storage temperature.

The space-heating performance of the heat pump was somewhat worse than would have been predicted from the temperature lift alone. This discrepancy was probably due to a combination of window opening behaviour and the building fabric performing less well than might be expected from simple assessment. The reason for this requires further investigation, but may be due to factors such as badly installed loft insulation or cavity wall insulation.

Nevertheless the combined effect was not sufficient to render system A the worst-performing system at any time, and the monthly performance factor remained over 2 throughout the whole annual cycle.

This type of analysis has implications for organisations such as social landlords who may wish to install a large number of heat pumps in similar properties, and suggests the possibility of beginning to quantify expected performance in any given case from knowledge of a few important factors, together with a reasonably-sized initial sample of dwellings which are monitored in detail. The sub-set of important factors enabling estimation of relative performance might be reduced to something like the following:

1. Measurement of internal living room temperatures and external temperatures

2. Measurement of temperature of fluid from ground loop (surface temperature probe)

3. Data on compressor cycling behaviour, via measurement of heat pump electricity consumption.

4. Measurement of DHW storage tank temperature. 
All of the above observations and measurements can be obtained relatively easily and cheaply and can be of considerable diagnostic benefit to building owners or system installers. Where relatively high rates of compressor cycling are identified which are not due to a particularly narrow space-heating hysteresis setting, then further investigations should be undertaken to assess whether the cause is poor building fabric or occupancy behaviours such as window opening (or both in combination).

Similarly, where electricity consumption is higher than the average for the type of system, and compressor cycling behaviour is normal, then the three other measurements identified above may be used in combination to assess whether this is due to high domestic hot water storage temperatures, or to a high space-heating temperature lift. The latter may be a result of high internal demand temperatures (i.e. a matter of occupant choice), or a result of poor ground-loop performance that requires further investigation and possible remedial action.

Furthermore, for the purposes of the Renewable Heat Incentive scheme, if monitoring is required at a domestic level in order to assess output for payment (rather than using a “deemed” output for a given system), it may be sufficient to divide dwellings into similar groups, to monitor a proportion only in detail, and estimate the remainder from a knowledge of a similar sub-set of parameters. Clearly further work would be required to establish and validate such a procedure on a wider basis.

\section{Acknowledgements}

The authors would like to thank the Engineering and Physical Sciences Research Council (EPSRC) and E.ON UK for providing the financial support for this study as part of the Carbon,Control \& Comfort project (EP/G000395/1). 
We are also grateful to Dr P. Boait of De Montfort University for helpful suggestions regarding the heat loss analysis.

\section{References}

[1] DECC (2011) Renewable Heat Incentive. London, March 2011.

[2] Energy Saving Trust (2010) Getting Warmer: a field trial of heat pumps. London, September 2010

[3] DCLG (2006) A Decent Home: Definition and Guidance for Implementation. London, June 2006.

[4] Boait, P.J., Fan, D. and Stafford, A., Performance and control of domestic ground-source heat pumps in retrofit installations. Energy and Buildings 43 (2011) 1968-1976

[5] Nordman, R., Andersson, K., Axell, M., Lindahl, L. (2010) “Calculation methods for SPF for heat pump systems for comparison, system choice and dimensioning” SP Report 2010:49, Energy Technology, SP Technical Research Institute of Sweden.

[6] Stafford A. Long-term monitoring and performance of ground-source heat pumps. Buildings Research and Information (in press).

[7] Wingfield J., Johnston, D., Miles-Shenton, D. and Bell, M. (2010) Whole House Heat Loss Test Method (Co-heating). Leeds Metropolitan University 2010. Available from: www.leedsmet.ac.uk/as/cebe/index.htm Accessed October 2011. 
[8] ATTMA (2007) Measuring Air permeability of Building Envelopes. Technical Standard 1.

[9] Building Regulations Approved Document L1A (2006 edition) Conservation of Fuel and Power. Crown Copyright, London 2006. 


\section{Figure Captions}

Fig 1: Month by Month Performance Factor of System A, compared with the maximum and minimum performance factors from all 10 systems.

Fig 2: Month by Month Electricity Consumption of System A, compared with the maximum and minimum electricity consumptions from all 10 systems. .

Fig. 3: Surface temperature at top of DHW tank. (Daily average calculated as a mean from data sampled at 10 minute intervals)

Fig 4: Daily Average Living Room and Bedroom Temperatures for system A (July 10 to February 11). (Daily average calculated as a mean from data sampled at 10 minute intervals).

Fig 5: Daily Average living room temperatures - all systems. (Daily average calculated as a mean from data sampled at 10 minute intervals).

Fig 6: Daily Average Temperature of fluid from Ground Loop for all 10 systems (November/December 2010). (Daily average calculated as a mean from data sampled at 10 minute intervals).

Fig. 7: Compressor cycling in System A.

Fig. 8: Correlation of Space-heating Compressor Cycling with Estimated Daily Heat Loss rate (6 co-located systems). 
Table 1: Compressor Cycling behaviour for six systems over 2 days.

\begin{tabular}{|c|c|c|c|}
\hline Dwelling Code & Cycles (Total) & Cycles (DHW) & Cycles (SH) \\
\hline 5 & 47 & 15 & $\mathbf{3 2}$ \\
\hline 6 & 60 & 9 & $\mathbf{5 1}$ \\
\hline 7 & 31 & 12 & $\mathbf{1 9}$ \\
\hline System A & 65 & 13 & $\mathbf{5 2}$ \\
\hline 9 & 40 & 13 & $\mathbf{3 9}$ \\
\hline
\end{tabular}

Table 2: Results of pressurisation testing

\begin{tabular}{|c|c|c|c|c|c|c|}
\hline \multirow[t]{2}{*}{$\begin{array}{l}\text { Dwelling } \\
\text { and Date }\end{array}$} & \multicolumn{2}{|c|}{$\begin{array}{c}\text { Air Permeability at } \\
\text { 50Pa: } \\
\text { Depressurisation }\end{array}$} & \multicolumn{2}{|c|}{$\begin{array}{c}\text { Air Permeability at } \\
\text { 50Pa: } \\
\text { Pressurisation }\end{array}$} & \multirow[t]{2}{*}{$\begin{array}{c}\text { Mean Air } \\
\text { Permeability }\end{array}$} & \multirow{2}{*}{$\begin{array}{c}\text { Air } \\
\text { Leakage } \\
\text { at } 50 \mathrm{~Pa} \\
\left(\mathbf{h}^{-1}\right)\end{array}$} \\
\hline & $\mathbf{m}^{3} /\left(\mathbf{h} \cdot \mathbf{m}^{2}\right)$ & $\mathbf{r}^{2}$ & $\mathrm{~m}^{3} /\left(\mathbf{h} . \mathrm{m}^{2}\right)$ & $\mathbf{r}^{2}$ & & \\
\hline $\begin{array}{l}\text { Co-heat } \\
\text { (Dwelling 3) } \\
18 / 1 / 2010\end{array}$ & 5.28 & 1.000 & 5.72 & 1.000 & 5.5 & 7.87 \\
\hline $\begin{array}{l}\text { Co-heat } \\
\text { (Dwelling 3) } \\
31 / 1 / 2010\end{array}$ & 5.33 & 0.997 & 6.32 & 0.998 & 5.83 & 8.34 \\
\hline $\begin{array}{l}\text { Dwelling } 6 \\
17 / 6 / 11 \\
\end{array}$ & 10.86 & 0.998 & 11.83 & 0.999 & 11.35 & 15.94 \\
\hline $\begin{array}{l}\text { System A } \\
17 / 6 / 11\end{array}$ & 6.16 & 0.999 & 6.39 & 0.998 & 6.28 & 8.78 \\
\hline
\end{tabular}




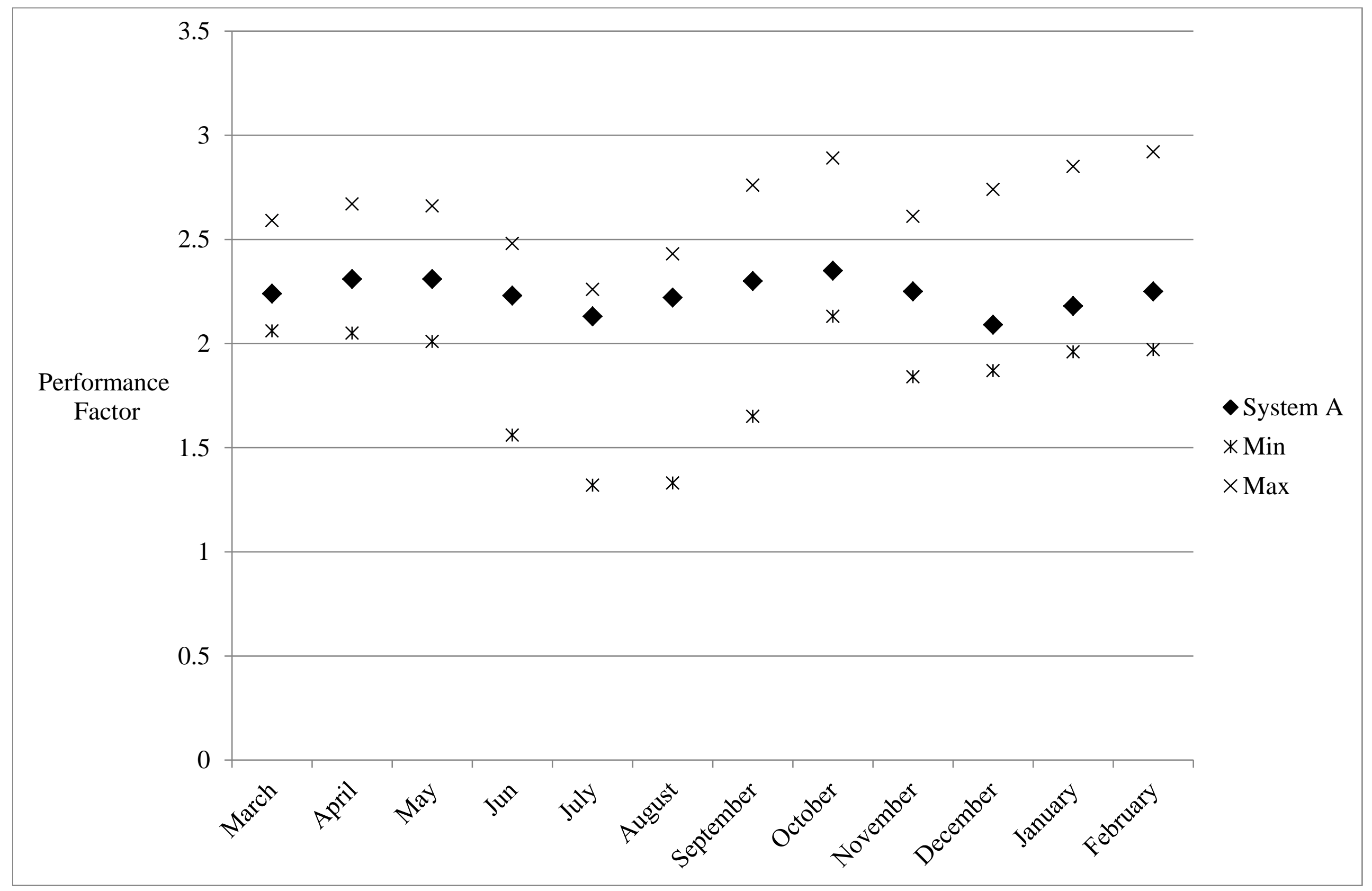




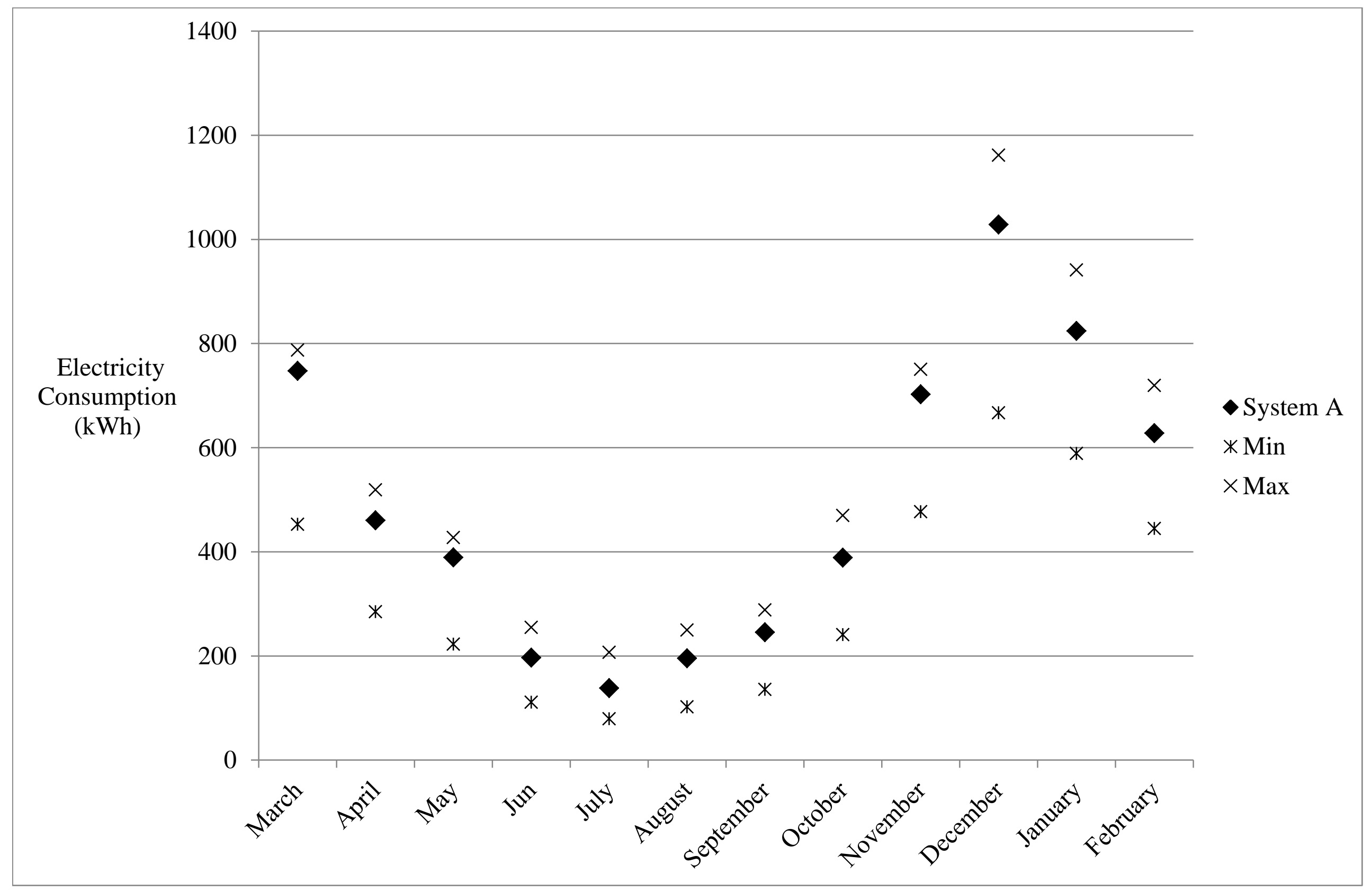




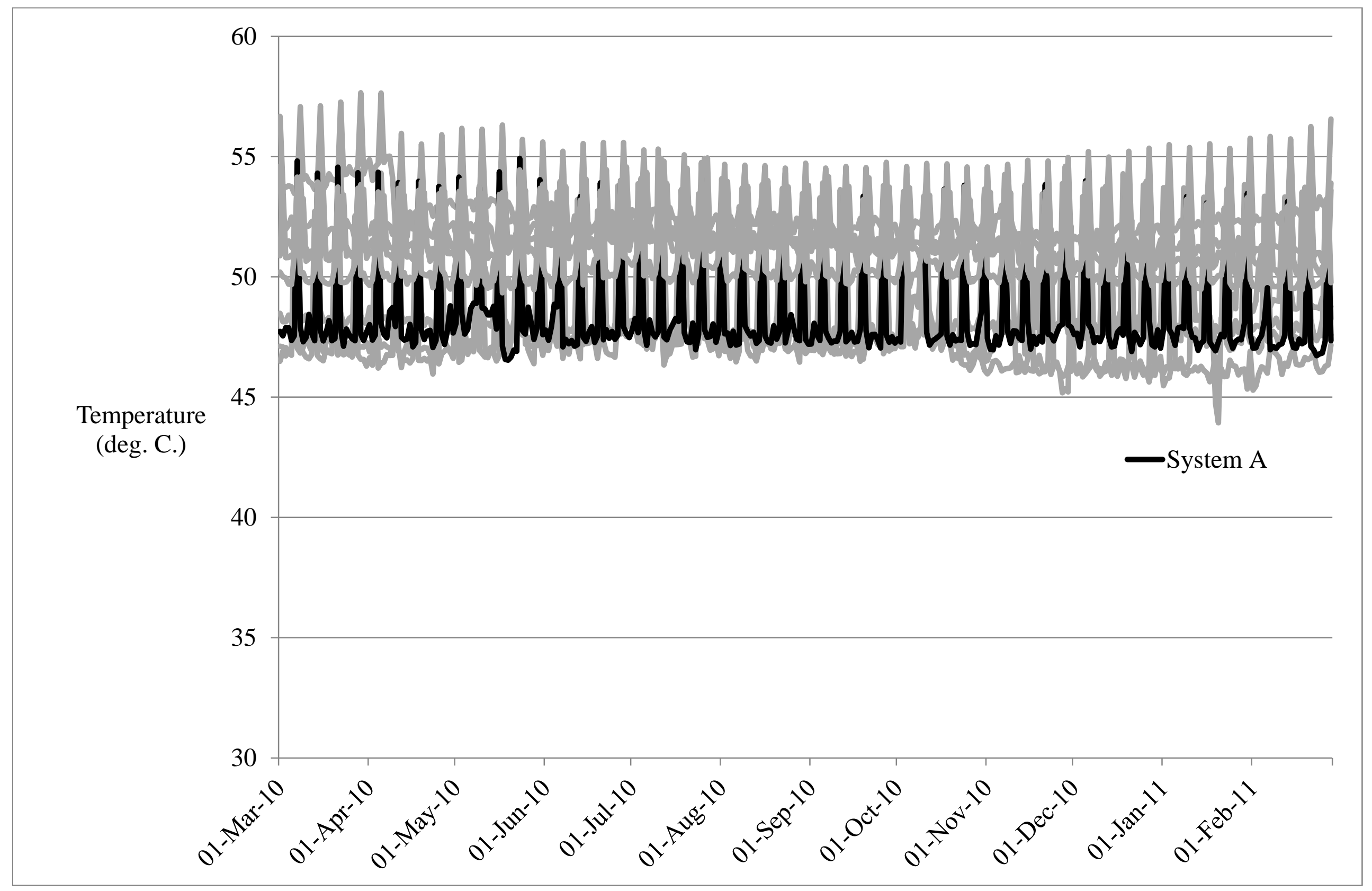




$$
=
$$




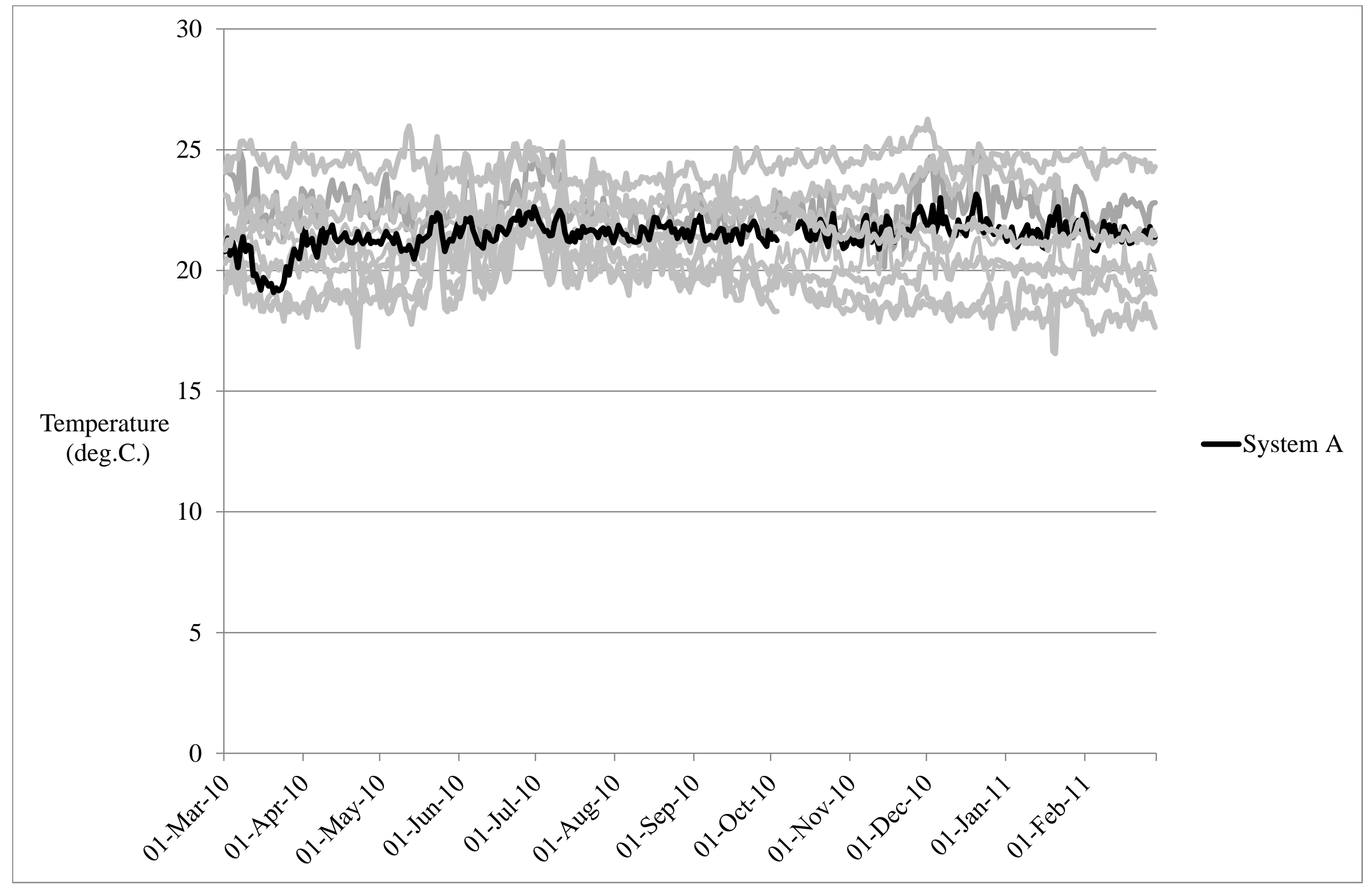




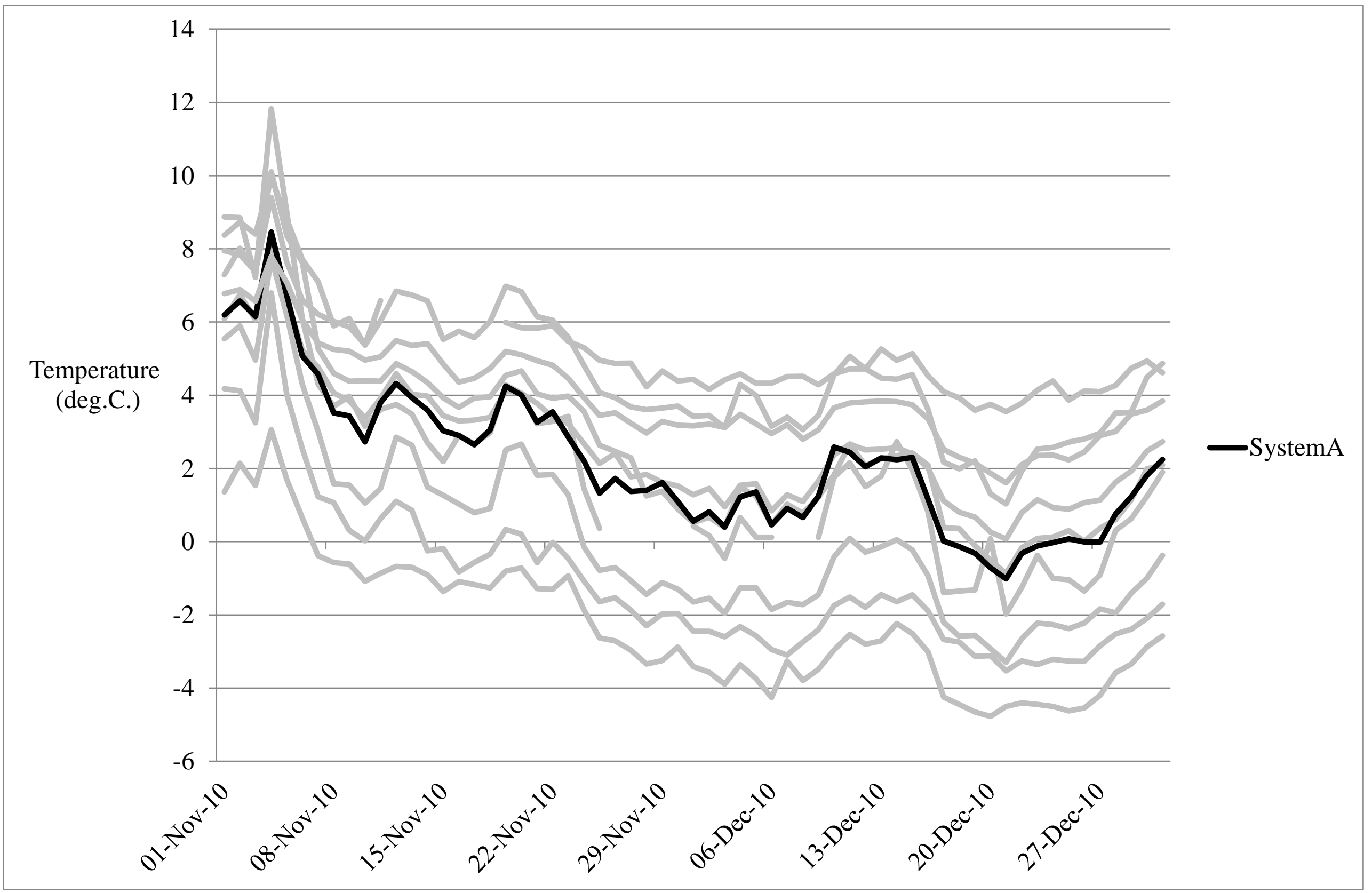




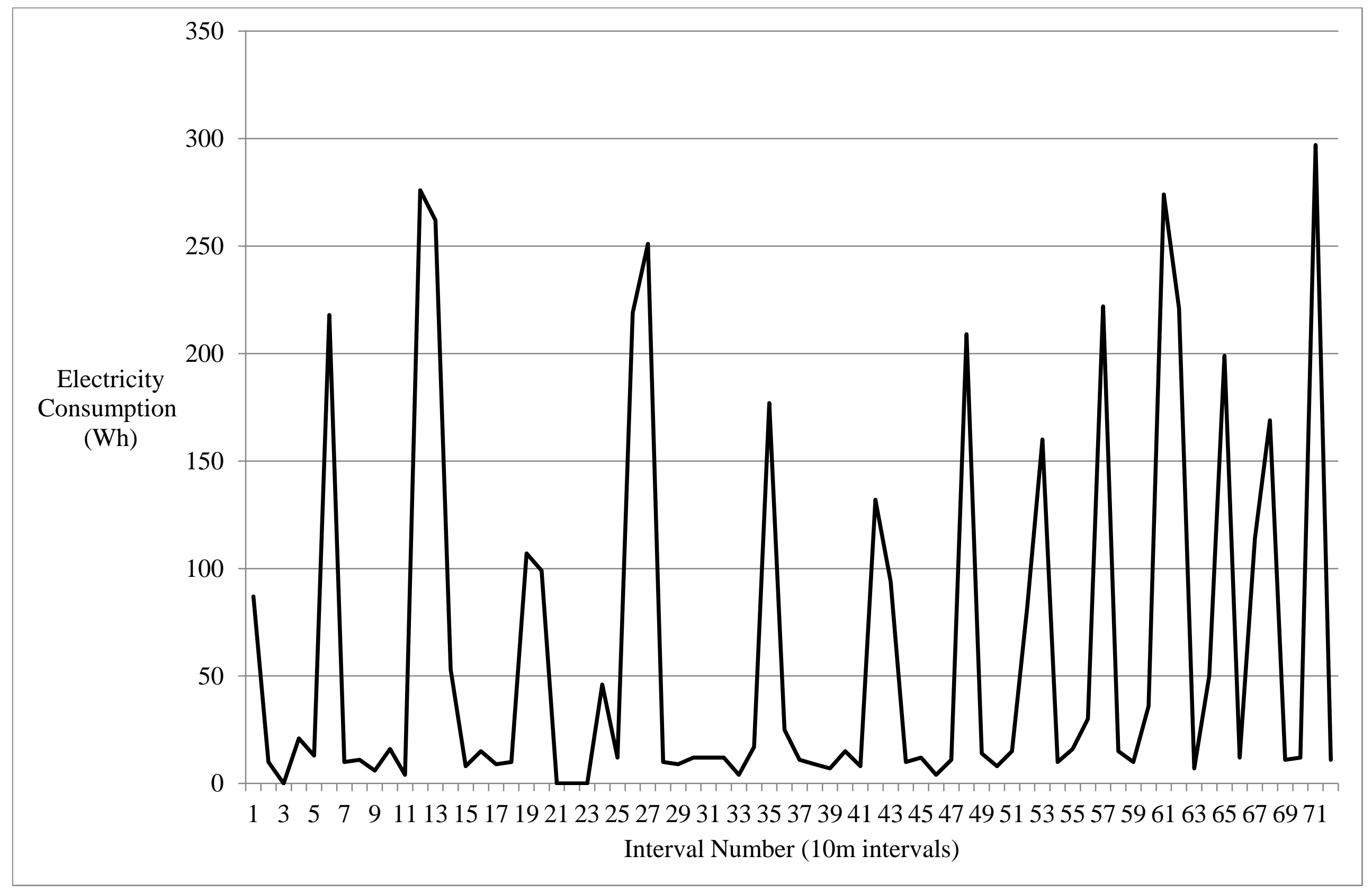




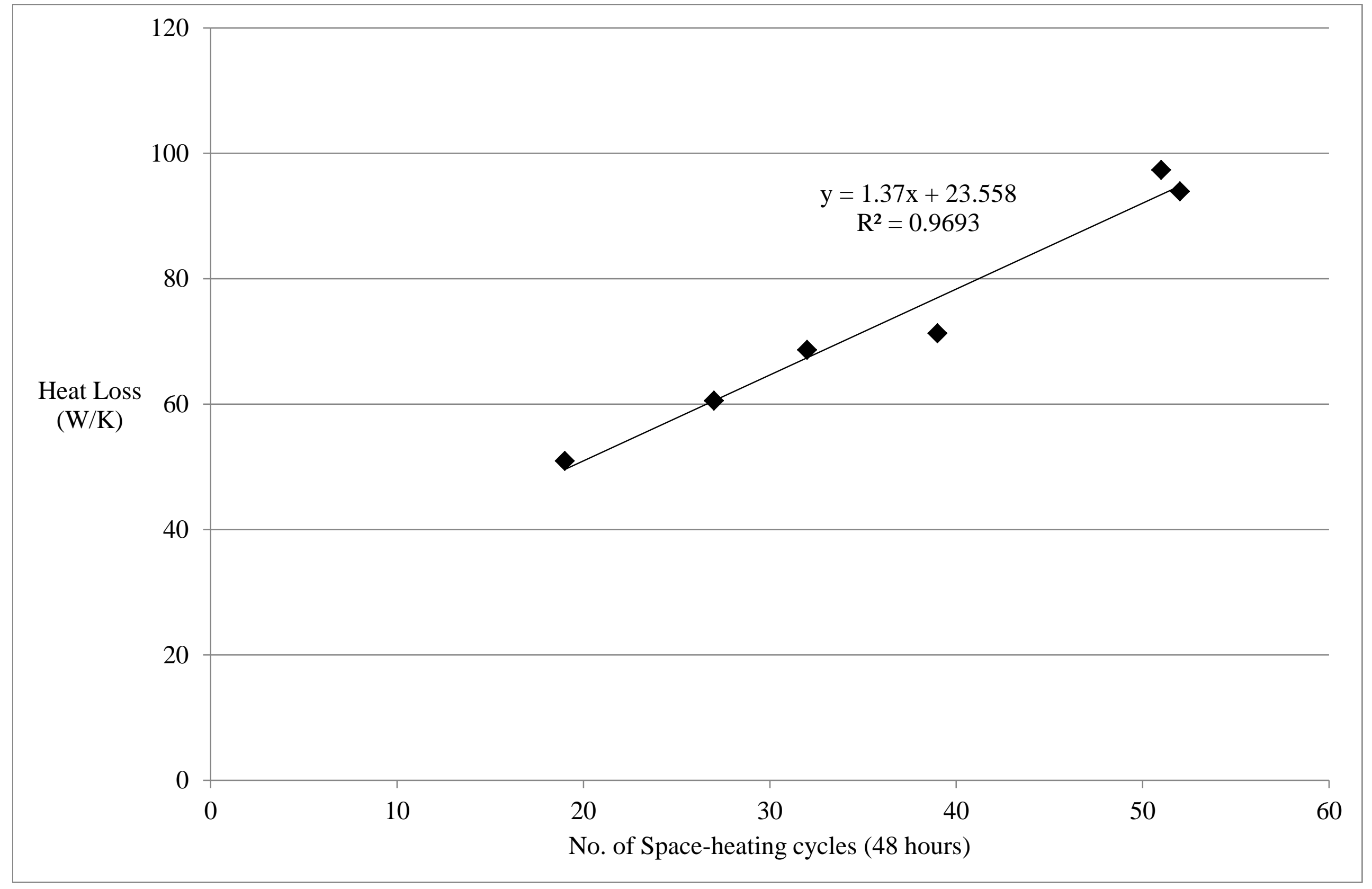

